\author{
Olaf Pedersen \\ Institute for History of Science \\ University of Aarhus, Aarhus, Denmark
}

\title{
Introduction
}

In Europe it has been customary to regard the ancient Greeks as our intellectual ancestors. Greek science was seen as the fountainhead from which modern European science ultimately derived both its existence and its characteristic features. This was not a completely empty idea. Each time a modern astronomer mentions a planet, the perigee and apogee of its orbit, its periods and their various anomalies, he is using so many Greek words. Moreover, until about a hundred years ago the extant works of the Greeks were the earliest scientific texts known to European scholars so that Greek science acquired a unique position in the European mind, and that ancient Greek culture in general became 'classical' and thus an ideal model or pattern for civilization as such. In consequence, the traditional European History of Science became an account of how science arose among the Greeks, how it penetrated into other cultural areas, and how it was sometimes eclipsed and again reborn in one of the so-called 'renaissances' of which European historians are so fond to speak.

That this account was not the whole truth was realised already by the ancient Greeks themselves. They were well aware of being newcomers to the world of science and not afraid of recognising the merits of their predecessors. On the other hand, the actual Greek knowledge of preGreek science was always vague and often fanciful although some of the more critical minds of the classical world refused to believe in the more extravagant tales, e.g. the rumour that the Chaldaeans had astronomical records inscribed on bricks and going back to 470000 years before the Flood. Therefore,classical scholarship paid 1ittle or no attention to the few and confused references to earlier science which are scattered throughout the works of the ancient authors.

This situation prevailed until the classical text began to be supplemented by new literary material stemming from the Middle East. The recovery and interpretation of the clay tablets of the 'Babylonians' proved the existence of an astronomical tradition spanning from about 1800 B.C. to the year A.D. 75. These texts revealed a highly developed mathematical astronomy which reached its peak in the last three or four centuries B.C. at the same time as the Greeks began to attack astronomical problems in a serious way. At first sight this new material seemed to underline the unique and original character of Greek astronomy. But slowly some evidence began to appear of a certain interaction between 
the two cultures and eventually European historians of science realised the necessity of re-examining the history of Greek astronomy in the light of what the Babylonians had achieved.

\section{The Scientific Revolution}

It all began in an extremely modest way. The great Homeric epics from about 800 B.C. reveal a very scanty knowledge of astronomical phenomena. A few fixed stars and a couple of constellations are named, and Phosphoros (the Morning Star) and Hesperos (the Evening Star) are mentioned but not identified as the same planet Aphrodite (Venus). The fact that the sun is closer to the horizon in winter times than in the summer is accounted for by saying that the sun-god, Helios, has gone away to the land of the Ethiopians. All phenomena of nature are seen as the results of the voluntary decisions of a great number of divine beings each of whom is responsible for a particular group of phenomena. In consequence, the behaviour of nature could be described in ordinary human language as it had evolved as a means of communication between human beings acting from motives of the same kind as those ascribed to the gods of nature. Thus the account of nature became a discourse about its gods. This mythological approach to nature is found everywhere among ancient peoples. On the one hand, it made nature familiar to man since it was governed on the same principles as human society. On the other, it made the relation between man and nature very uncertain since the acts of the gods were wilful and arbitrary: Who could be certain that the sun-god would return next spring? Here we are at the origin of both magic and divination.

Among the Babylonians, who identified the superior gods with the sun, moon, and planets, astrology occupied a predominant position. From old Babylonian times onwards thousands of astrological omens reveal the existence of professional astrologers who kept watch over the skies and reported notable events to the king in order to enable him to govern, at the same time as they were responsible for the upkeep of the calendar. This connection between astronomical observation and astrological divination was destined to play a decisive role. Over long periods of time it was impossible not to notice a number of regularities in the phenomena of the heavens. So there was only a short step to the actual prediction of future celestial events by more and more sophisticated mathematical methods which in the last four or five centuries B.C. led to procedures for determining new and full moons and synodic phenomena of the planets. This was achieved in a purely phenomenological way and, as far as we can see, without any reference to the cosmological ideas of the structure of the world which must have existed a1so in Mesopotamia.

Also in the Greek world one must have felt the essential unpredictability of natural phenomena in a mythological discourse as something annoying. This may well have been one reason why the Ionian thinkers in the Greek settlements in Asia Minor began to experiment with a new form of account. This happened in the sixth century B.C. which everywhere in the world seems to have been exceptionally fertile: In India the great Gautama became the Buddha in search of enlightenment, and in Israel the great prophets expelled the many gods of nature in favour of a single God as 
the creator and upholder of everything according to His unchangeable precepts. What Thales and his followers did was to try to account for all events in nature on the assumption that there are inexorable laws inherent in nature itself of such a force that even the gods cannot resist them. Two centuries after the first tentative efforts of the Ionians the new language of science can be studied in the works of Aristotle where terms like 'cause' and 'effect', 'matter' and 'form', 'substance' and 'accidence', 'chance' and 'necessity' and many others were defined as vehicles for a new type of natural discourse in which uncertain wilfulness was replaced by constant laws which are accessible to the human mind through experience and reason and can be disclosed through natural research. It is obvious that here we are at the roots of that attitude which has cver since been the hallmark of science.

\section{The Initial Period}

In a somewhat simplified way it is possible to discern two different tracks along which the early Greeks tried to find the laws which govern the universe at large. The Ionians embarked upon a vast scheme of cosmological investigations embracing everything which exists. This concept was denoted by the word kosmos which means 'order', with strong overtones of 'beauty'. Here they made rapid progress. Thales still saw the earth as a flat, round disc surrounded by the ocean. His successor Anaximander gave it the shape of a cylindrical drum, suspended in the middle of a vast space where it remains at rest "because it has the same distance from everything", as he said with a charming application of the principle of symmetry - later generalised into the principle of sufficient reason - which has remained through the ages as a useful heuristic tool for scientific reasoning. Outside the earth Anaximander described the 'stars' or planets as inclined wheels with hollow rims filled with fire which can be seen through a small opening. Other philosophers denied the existence of the sun as a material body, and it was not until after the fall of a large meteorite, in $467 \mathrm{B.C.,}$ that Anaxagoras declared the sun to be a red-hot stone larger than Peleponnes. It was also he who realised that the moon gets its light from the sun, an idea which provided him with the correct explanation of eclipses. Physical cosmology has begun to strike roots.

While the Ionians thus tried to account for the universe in terms of interacting material bodies governed by the law of cause and effect, the so-called Pythagoreans - to use Aristotle's sceptical expression adopted a very different approach. They flourished in the century preceding 400 B.C. when their organisation began to dissolve and other philosophers came to be influenced by their teaching. The Pythagoreans tried to connect the phenomena of nature by means of mathematical relations, in contrast to the Ionian idea of physical forces acting on material bodies. There is no serious reason to doubt the tradition that they discovered the fact that the harmonic properties of the musical scales can be mathematically expressed by ratios between the small integers 1, 2, 3, and 4, and that this led them to establishing the number theory contained in Book VII of the Elements of Euclid.

Since number theory proved to be successful in acoustics it was tempting 
to try its power also in other fields. According to Aristotle this led to numerological speculations. Since the sum $1+2+3+4$ equals the sacred number 10 the early Pythagoreans seem to have assumed the existence of ten celestial bodies, including the earth and the famous 'counter earth', circulating around a central fire. This idea was abandoned by the later Pythagoreans who placed the earth in the middle of the universe with the other bodies circling around it at such speeds and distances that their motions produce the inaudible 'harmony of the spheres'. Likewise they were responsible for the principle that all celestial motions must be circular and uniform with respect to the centre.

\section{Originality and Interaction}

In this account there is nothing which could not have been said one hundred years ago. Today we have to make an attempt to distinguish between those ideas which originated among the Greeks and those which they imported from the outside world. In fact, there are many indications that both cosmological and astronomical ideas percolated into Greece, and that they all came from the East. Thus, Thales's idea that the physis, or original matter, of everything was water seems to reflect the primordial role ascribed to water in many near-Oriental myths of the origin of the world. Anaximander ordered the heavenly bodies such that the sun is the highest, then comes the moon, next the fixed stars, and finally the five planets closest to the earth; this order is identical with the standard Persian system known from the Avesta. As for the problems of time, Anaximander believed the physis to be eternal and performing an eternal motion from which innumerable worlds would emerge and again disappear. Anaximenes taught that there will always be a world, but not the same world, since it becomes different at different times according to certain periods of time. Also Heraclitus is credited with a 'Great Year' of 18000 years. It is difficult not. to connect the belief in definite periods of the world with Eastern ideas, such as the 12000 years of the Persians, or the even longer periods of both Babylonian and Indian systems. With the Pythagoreans the foreign influence on Greek thought is even more obvious. Thus they thought of the order of the world in dualistic terms such as odd and even, one and many, good and evil, and light and darkness, which are clearly reminiscent of Zoroastrian principles. Un-Greek is also their belief in the transmigration of souls. Finally they also assumed a strictly cyclical theory of time.

A11 this is sufficient to show that some of the fundamental ideas of the early Greek cosmologists and philosophers had their counterparts in the East and that it is reasonable to assume a direct or indirect transmission. An even stronger suspicion appears if we cross from the realm of ideas to the realm of numerical relations. It is well known that the so-called Metonic period of 19 solar years $=235$ synodic months was known in Mesopotamia before Meton's time. Since it is extremely unlikely that Babylonian astronomers would have anything at all to learn from Greek scholars of the fifth century B.C., the inference must be that the Metonic period was imported from Babylon. 


\section{Geometrical astronomy}

In the beginning of the fourth century B.C. Greek intellectual life was dominated by the philosophy of Plato who was deeply influenced by Pythagorean doctrines and hostile to the naturalistic attitude of the Ionians. But his mathematical proclivities appear in many places, and it is worth noticing that the first known attempt to create a proper planetary theory was made by the mathematician Eudoxus who was, for a time, Plato's collaborator in the Academy in Athens. Eudoxus assumed each of the planets to be carried by a system of spheres, a11 of them concentric with the earth. In each planetary mechanism the individual spheres had periods and axes of rotation arranged in such a way that the apparent motion of the planet would conform more or less to the observed phenomena, including direct and retrograde motions. However, we have no evidence that the system of Eudoxus was ever used for actual predictions of planetary positions. It also had certain defects. Thus Calippus drew from it the correct conclusion that the sun would move with constant speed on the ecliptic which implied that the four seasons would be of equal length. Towards the end of the fourth century the theory was finally destroyed when Autolycus pointed out that no system of concentric spheres would explain the varying distances of the planets from the earth.

The mathematical theory of concentric spheres was also the basis of Aristotelian cosmology. Aristotle maintained the principle of experience. This meant, firstly, that the mathematical properties of nature were not obtainable from numerological speculation, but only from observations. But secondly, Aristotle wished to treat the celestial world as a material structure like the rest of the universe. In consequence, he replaced the abstract mathematical spheres by spherical shells (also called 'spheres') made of a particular form of celestial matter called aether, an idea founded on Aristotle's belief in the eternity of the world; an everlasting, circular motion of the heavens could not be produced by the four sublunary elements, but presupposed a different kind of matter. Another feature was the finite character of the world. Outside the outermost sphere of the fixed stars there was nothing - not even an empty space. This followed partly from the fact that the notion of an extended vacuum was incompatible with Aristotle's theory of dynamics, partly from the lack of a proper word for abstract 'space' in the Greek language. Thus Aristotle connected celestial mechanics with the laws of physics at the cost of assuming different laws for the celestial and the terrestrial parts of the universe. His cosmology satisfied 'philosophers' and 'physicists' for two thousand years as a crude and easily grasped 'physical' model of the universe, but was useless for astronomers since it suffered from the defects of the homocentric systems in general,

In a more general sense the system of Eudoxus was of immense importance as the first exercise in a type of research in which the Greeks were to become masters - the 'saving of the phenomena' by means of kinematical models of a purely geometrical nature. This led to the development of spherical geometry as a tool for astronomers. 
Geometry and astrology

The emergence of geometrical models gave Greek astronomical theory a form which was very different from that of the Babylonian astronomers whose work can be summarily described as an attempt to determine the times and positions of a discrete succession of synodic phenomena without paying much attention to what happened in between. On this background it is understandable that they preferred mathematical tools operating with discrete values of a set of astronomical variables, generated by linear zig-zag or step functions. In contrast to such procedures the geometrical models of the Greeks. would work in a continuous way. This fact enabled them to extend the scope and purpose of theoretical astronomy so that it would be possible to solve the problem of determining the position of a celestial body at any given time. It is, therefore, a historical problem if there were intellectual features in the Greek world which would welcome the continuity of geometrical models. Here we may look to astrology which was rooted in the astral religion of Mesopotamia. In Greece the religious background was different and before 400 B.C. there are very few testimonies of astrological beliefs on Hellenic soil, although the way was paved for astrology by the Pythagorean doctrine of world cycles and Plato's description of man as a microcosm closely related to the macrocosm. But gradually Babylonian astrology began to make an impact in the Greek world, and from the third century B.C. astrology spread all over the Mediterranean world. However, this would have been irrelevant to the status of geometrical models if the nature of astrology had not suffered a significant change. Originally astrology was a public affair concerned with omens of future events affecting society as a whole. But from around 400 B.C. astrologers began to predict also the fortunes of individuals from the position of the planets relative to the zodiac at the time of their births, as attested in a cuneiform text from 410 B.C.

This change had important consequences for the astronomical theories on which astrological predictions were made. For whereas the old public or 'judicial' astrology was concerned with the prediction of (mainly) synodic events at certain times in the future, personal 'horoscopic' astrology was faced with the problem of determining planetary positions at arbitrary points of time in the past. It goes without saying that for this purpose a continuously working geometrical model would have a great advantage over the essentially discrete procedures of Babylonian astronomy. There is the difficulty with this assumption that the first Greek horoscopes belong to the second century B.C. and that many Greek astrologers worked by methods derived from Babylonia. However, this does not preclude the idea that a reliable geometrical theory would have been welcomed by astrologers. It only shows that it took a long time before such a theory was forthcoming.

This astrological perspective on theoretical astronomy is, of course, not a sufficient explanation of the Greek preference for geometrical models which also had the advantage of lending themselves to cosmological interpretations; and since from the very beginning of scientific thought the Greeks were seriously concerned with the physical structure of the universe, a geometrical model would to some extent satisfy their growing recognition of the unity of science as an all-embracing account of nature. 


\section{Hellenistic Astronomy}

The fourth century B.C. had made a new start by investigating a detailed model of planetary motions. This attempt had failed and in the following period Greek astronomers tried to find ways to overcome the defects of the concentric models. Now the scene moved from Hellas and Italy to the new city of Alexandria in Egypt where a kind of Royal Institute with impressive libraries and other facilities for study was able to attract scholars from many parts of the ancient world, among them many astronomers. Here the Aristotelian scheme was generally adopted with that order of the planets which became canonical until the time of Copernicus, defined according to their periods of revolution. Also the absolute finitude of the universe became part of this scheme, despite the attempt made by Stoic philosophers to imagine some sort of emptiness beyond the ultimate sphere. The only serious alternative to Aristotle's cosmology was due to Aristarchus of Samos who, about 280 B.C. proposed a heliocentric model with the earth revolving like a planet in an orbit centered on a motionless sun in the middle of the world. This idea was met with general disbelief and ignored by both 'physicists' and astronomers because the earth had to be without motion for physical reasons, and because the system was not sufficiently provided with numerical parameters to make it possible to calculate positions.

On the other hand, Hellenistic astronomers made a new departure in cosmology by their attempts to determine the sizes and mutual distances of the earth, moon and sun by means of observations and actual measurements. The beginning seems to have been made by Aristarchus who estimated that the sun is 18 to 20 times as far away from the earth as the moon. Somewhat later in the third century B.C. Archimedes found a good value of the apparent diameter of the sun, obtained by direct observation with an instrument constructed for this purpose; and about the same time the circumference of the earth was determined by the Alexandrian librarian Eratosthenes. Such results point to a new awareness of the importance of quantitative observations, often made with new types of instruments such as globes, rings, quadrants, armillary spheres, and others which were developed over al1 the 700 years of Hellenistic science. Observational astronomy began shortly after 300 B.C. in Alexandria with a certain Timocharis and his successor Aristyllus. Their results seem to have been expressed in degrees and fractions of a degree; if this is not a later reformulation we must conclude that the first Alexandrian astronomers were, in fact, conversant with the Babylonian division of the circle (but not with the sexagesimal system as such) although both Aristarchus and Eratosthenes used earlier methods.

Thus the third century B.C. was a period of transition during which at least some features of Babylonian science were transmitted to the Greek world. This is confirmed by the so-called 'Eudoxus Papyrus' from the beginning of the second century B.C. Its unknown author tried to determine the variation of the length of daylight over the year. He used an example in which the longest day is 14 hours and the shortest 10 hours which were the standard values for Alexandria. In his solution he made use of a linear zig-zag function and it is difficult not to see here an unmistakable Babylonian influence, although the author used oldfashioned Egyptian unit fractions of an hour instead of minutes. Around 
150 B.C. the Alexandrian astronomer Hypsicles dealt with a similar problem by another application of one of the mathematical tools of the Babylonians.

Thus Hellenistic astronomy showed both originality and dependence long time before the theoretical problems of planetary motion were attacked in a serious way. However, around 200 B.C. the brilliant mathematician Apollonius of Pergae brought planetary theory out of the deadlock in which Eudoxus had left it. He did not question the old dogma that celestial motions must be circular and uniform with respect to the centre, but investigated two geometrical models in which such motions would, nevertheless, show apparent anomalies to the observer. In the excentric model the observer is outside the centre of a circle on which the planet performs a uniform motion. In the epicyclic model the observer is at the centre of a circle (later called the deferent) on which the centre of an epicycle moves uniformly, while the planet moves uniformly on the epicycle. Apollonius was also able to state that the two anomalies must be identical under certain conditions, and was even able to show how one of the models could be transformed into the other by a geometrical inversion. This revealed that one and the same phenomenon might be 'saved' by different geometrical models; thus it was impossible to draw cosmological conclusions regarding the structure of the world from a geometrical model, a fact which gave rise to fervid discussions among supporters of a 'physical' or a 'mathematical' ideal of theoretical astronomy. On the other hand, there is no doubt that Apollonius's investigations stimulated a new interest in geometrical models of various types in which the resulting anomaly would depend on the choice of the parameters and the sense in which the circular motions were performed. These remarkable achievements owed nothing to the Babylonians, but represented a typical Greek preoccupation with theories shaped in a geometrical form.

\section{The Acme of Greek Astronomy}

Although the astrologer Vettius Valens (about A.D. 160)

maintained that he had used lunar tables by Sudines, Kidenas (two Babylonian astronomers) and Apollonius, there is no real evidence that the latter put his geometrical models to practical use with parameters drawn from empirical data. This important step was taken by the greatest of all ancient astronomers, Hipparchus (about 160 to 125 B.C.). Almost all of his many works are lost and the results of his achievements can only be inferred from passages in Ptolemy. Extant is his Commentary on a Phainomena by Aratus from about 280 B.C. in which he surveyed the constellations with a wealth of information about positions of several hundred fixed stars, given in various ways which show that Hipparchus had not systematised his celestial frames of reference; in particular it is worth noticing that he only gives ecliptic longitudes for two stars, and no latitudes at all. That he placed the zero point of the ecliptic at Aries $0^{\circ}$ shows that here he was independent of the Babylonians who put it at Aries $8^{\circ}$. Of interest is also his solution of the problem of how in each geographical 'climate' the length of the longest day is connected with the solstitial altitude of the culminating sun; here he applied a purely algebraic method. In other problems he used geometrical 
methods, and everything points to the conclusion that he knew how to apply stereographic projection to solve spherical problems, thereby laying the foundation for the later theory of the astrolabe.

Even more remarkable was Hipparchus's introduction of trigonometrical methods in astronomical calculations by means of a (now lost) Table of Chords which enabled him in principle to solve all problems of plane triangles by calculation and was the immediate basis for his epochmaking work on the theory of the sun. The unequal length of the four seasons implied an annual anomaly of the apparent motion of the sun which made it impossible to use a simple theory of uniform motion on a concentric orbit, so it was natural to try the eccentric (or the equivalent epicyclic) model of Apollonius. The problem was whether this model could be provided with proper parameters, and whether it would then simulate the apparent motion of the sun with sufficient precision. The fundamental parameter was the length of the solar year which Hipparchus here took to be the Calippic year of $3651 / 4$ days. The length of the spring and summer seasons then led to the length of the corresponding arcs described by the sun on the eccentric circle. From these data and by means of a trigonometrical calculation Hipparchus was able to determine the apsidal line of the orbit and the ratio of the eccentricity and the radius of the orbit. There can be no doubt that he used the model to calculate a table of solar positions throughout the year, and that he found it satisfactory.

This transformation of the abstract model of Apollonius into a practical theory was a major step forward in the history of theoretical astronomy. Among other things it seems to have taught Hipparchus that an eccentric, circular orbit can be determined from only three data. This enabled him to attack the problem of the motion of the moon from its position at three different eclipses, these positions being obtainable from the times of the eclipses by means of the solar theory. The lunar theory of Hipparchus used a model with an epicycle on a concentric deferent. In order to establish its parameters it was necessary to know the different mean periods or the equivalent mean daily motions of the moon in longitude, anomaly, elongation and latitude. According to Ptolemy, Hipparchus obtained these data by calculation from "observations made by the Chaldaeans and in his [own] time", and it is certain that Hipparchus utilized several Babylonian period relations, such as 251 synodic months $=263$ anomalistic months and others, for two purposes, viz. to establish a reliable eclipse period in order to be able to check Babylonian eclipse records, and to find precise values of the lunar periods mentioned above. This led him to a value of the length of the synodic month which differed from the Babylonian value, 1 synodic month $=29 ; 31,50,08,20$ days, only by a fraction of a second. Thus the extremely precise parameters of the Babylonian lunar theory became an essential element of Hipparchus's work. There is no doubt that Hipparchus finally obtained a lunar theory which worked very well at new and full moons and enabled him to predict eclipses.

Out of the lunar theory came at least one unexpected discovery of the first importance. During two lunar eclipses in 146 and 135 B.C. Hipparchus determined the position of Spica to be roughly $6^{\circ}$ west of the autumnal equinox. Now in 294 B.C. Timocharis had observed an occultation 
of Spica and in 283 B.C. a conjunction between the same star and the moon. The dates of these events gave the longitude of the moon by means of the theory, with the result that relative to the equinoctial points Spica had moved about $2^{\circ}$ to the east in the 150 years between the two sets of observations. According to Ptolemy this was the way in which the precession of the fixed stars, or their secular motion in longitude, was discovered. Modern attempts to trace it back to the Babylonians have not met with scholarly agreement.

In the solar theory Hipparchus had assumed a sidereal year. The discovery of precession made it imperative to find a value for the tropical year the precise definition of which is first found in Hipparchus's lost work On the Length of the Year. His result was about 6 minutes too long, a fact of far-reaching consequence for European time-reckoning.

Hipparchus's significance for the history of astronomy cannot easily be overestimated. He gave theoretical astronomy a new start by his demonstration that it was possible to fit geometrical models to observational facts, a lesson which astronomy has never since forgotten. In this he was greatly assisted by his knowledge of Babylonian data; so also in his case we must admit the importance of what the neighbours of the Greeks had achieved, even if his own genius undoubtedly was of the Greek type.

The Final Effort

The 250 years which separated Hipparchus from Ptolemy seems to have been a rather stagnant period. From this interval is a textbook or Isagoge by Geminus who adopted Hipparchus's theory for the sun, but ignored his value of the length of the tropical year and was unaware of the discovery of precession. For the anomalistic month he used a value taken from Babylonian astronomy, and when he calculated the motion of the moon in anomaly he left the geometrical model on one side in favour of an arithmetical scheme; it was obviously derived from the Babylonian system B and provided with Babylonian parameters. All this shows that the influence from the East was increasing and able to compete with the proper Greek tradition. On the other hand some real progress was made in spherical astronomy by the work of Menelaus who defined the concept of a spherical triangle and applied trigonometrical methods to the geometry of the sphere. This opened the whole field of spherical astronomy to numerical calculation of values which could be directly compared with the results of observations, and inaugurated a new era marked by the name of Ptolemy.

Unlike Hipparchus Ptolemy was not a full time astronomer. His purpose was to write comprehensive expositions of all branches of 'applied mathematics', such as astronomy, astrology, geography, cartography, optics and harmonics (the theory of music). That he stands out as the last of the great astronomers of Antiquity is understandable since his Almagest superseded most earlier works. But it must be borne in mind that the Almagest was no report on Ptolemy's own research. It was rather a manual or textbook, written in order to initiate advanced students in the methods of Greek astronomy, and in particular to show how one may construct geometrical models designed to save a great variety of 
phenomena, and how to provide them with numerical parameters derived from observations.

In the Almagest Ptolemy obviously wished to present solutions to problems which Hipparchus had left unanswered. According to Ptolemy, Hipparchus did not even make a beginning in establishing theories for the five planets, for although he had collected and systematised a number of observations of planetary phenomena he found that these were not in agreement with the hypotheses of the astronomers of that time. But no manual of astronomy could be complete if it ignored the motions of the planets, and there is no doubt that Ptolemy saw it as his task to supplement Hipparchus by trying to construct the missing planetary theories. This was an enormous programme and full of unforeseen difficulties. But first and foremost it was necessary to choose a well defined approach to mathematical astronomy as such, and here Ptolemy consistently discarded the algebraic methods of the Babylonians in favour of the geometrical models of the Greeks. Like his predecessors he made freely use of Babylonian parameters, period relations and records of observations; but the theoretical methods of the East left no trace in his work, neither in his reform of the lunar theory of Hipparchus, nor in his own account of the motions of the five planets which he described by an ingenious combination of epicyclic and eccentric circles the details of which we must here leave out of consideration.

\section{Conclusion}

This brief and incomplete survey of some of the main lines of Greek astronomical thought has indicated some of the points at which the traditional picture of the self-contained character of Greek astronomy has undergone revision. We have to admit that European astronomy is not indebted to the Greeks alone. Although they certainly used them in their own characteristic way, they themselves drew freely on observations and parameters of their predecessors in the land between the rivers. In consequence we must abandon the old idea of GraecoEuropean science as unique and independent. We know already something about the Greek debt to the Babylonians. To investigate the possible, but no doubt existing, relations between the scientific worlds of Greece and India is another task which may well prove to be one of the more fascinating fields of study for both present and future historians of astronomy. 


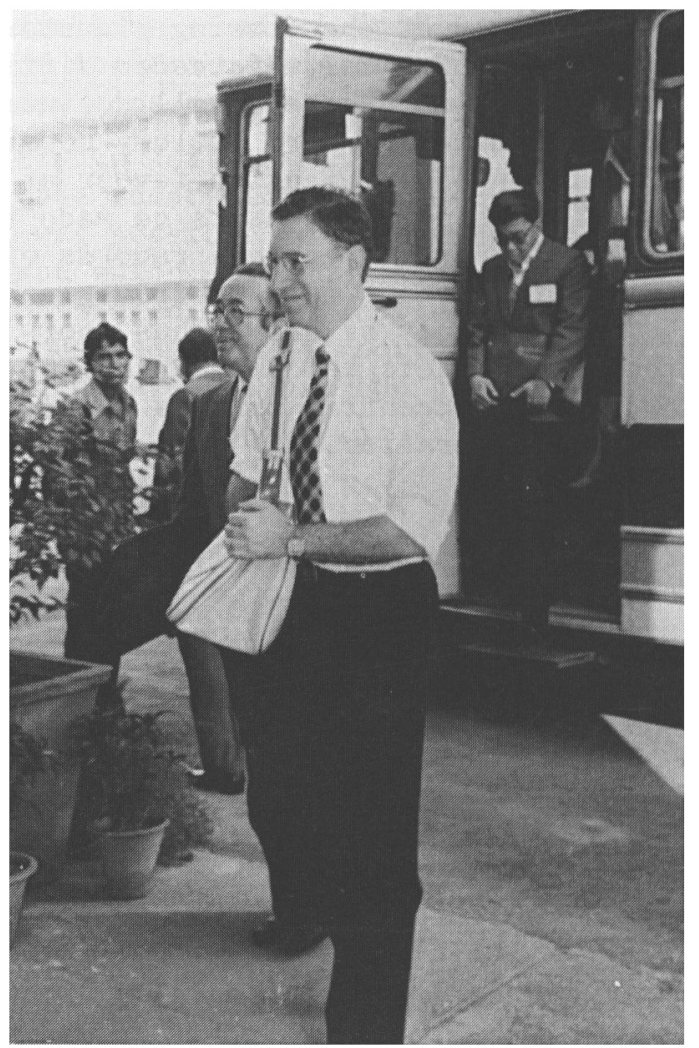

Shigeru Nakayama and Michel Teboul (Front two from left) 